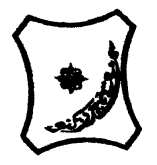

Bayero Journal of Pure and Applied Sciences, 10(1): 647 - 649

ISSN 2006 - 6996

\title{
DETERMINATION OF POLYPHENOLIC CONTENTS AND ANTIOXIDANT POTENTIAL OF LEAF EXTRACTS FROM Jatropha curcas (LINN)
}

\author{
*Ibrahim, N. S. and Idris, U.K \\ Department Pure and Industrial Chemistry, Faculty of Physical Science, Bayero University, Kano \\ P.M.B. 3011, Kano, Nigeria. \\ ${ }^{*}$ Correspondence author: nsibrahim.chm@buk.edu.ng
}

\begin{abstract}
The leaves of Jatropha curcas is well reputed for their traditional medicinal uses in Africa, therefore, the present study was carried out to assess the polyphenolic contents and antioxidant potential of the ethylacetate and ethanol leaf extracts of Jatropha curcas. The proanthocyanidin contents and ferric reducing antioxidant power (FRAP) assay had been used to determine antioxidant activity in both samples and results were compared with that of butylated hydroxyl toluene (BHT) and ascorbic acid as standards. The results showed that there is a strong correlation between total phenolic contents and antioxidant activity $\left(r^{2}=\right.$ 0.956) such that extract with higher phenolic content displayed the best antioxidant capacity. The polyphenolic content were expressed as $\mathrm{mg}$ of tannic acid equivalent per gram of extract and the concentrations of phenolic compounds were higher in ethanol extracts of $J$. curcas $(357 \pm 12.13 \mathrm{mg} / \mathrm{g}$ TAE) compared to ethylacetate extracts $(159 \pm 0.65 \mathrm{mg} / \mathrm{g}$ TAE). The antioxidant potentials of the plant extracts was estimated from their ability to reduce $\mathrm{Fe}^{3+}$ to $\mathrm{Fe}^{2+}$. The reducing power of the extracts were observed by change in color from yellow of the test solution that changed to various shades of green and blue depending on the concentration of the plant extracts. The results of the present study indicated that the ethanol extract is a potential source of natural antioxidants and may be a good candidate for pharmaceutical plant based products.
\end{abstract}

Keywords: Proanthocyanidin, phenols and antioxidants

\section{INTRODUCTION}

Phenols are aromatic compounds containing one orseveral hydroxyl groups directly attached to the benzene ring. According to the number of hydroxyl groups, phenols are classified as dihydric, trihydric and polyhydric. By the year 2005, thousands of polyphenolic compounds have been isolated from plants (Prior, 1995). There are many spectrophotometric methods for the quantification of phenolic compounds in plant materials. Based on different principles, these methods are used to determine various structural groups present in the phenolic compounds. Spectrophotometric methods enable either the quantification of all extracted phenolics as a group, or as specific phenolic substances (Shahidi, 2000).

Antioxidants are substances which are resistance against oxidative stress (i.e. ability to delay the oxidation of a substrate by inhibiting the initiation or propagation of oxidising chain reactions caused by free radicals) (de Oliveira, et al., 2012). It plays important roles to prevent fats and oils from becoming stinking and protects human body from detrimental effects of free radicals. Synthetic antioxidants have been used worldwide for decades. However, they are being scrutinized due to possible toxic and carcinogenic effects (Kinnula and Crapo, 2004). As a result, an intense new area of research has been developed concerning the search for identification and characterisation of naturally occurring antioxidants. Natural antioxidants are more ideal as food additives, not only for their free radical scavenging properties, but also on the belief that natural products are healthier and safer than synthetic ones; thus they are more readily acceptable to the modern consumers (Barbosa, et al., 2009).

$J$. curcas is drought resistant shrub tree belonging to the family Euphorbiaceae and is widely distrivuted in a semi cultivated areas in America, Africa and South-East Asia (CanoAsseleih, 1986). Commonly known in Hausa as "Bini da zugu", it is well known to have several ethnomedicinal applications some of which include; fever, purgative, joint rheumatism, anthelmintic, inflammation, skin diseases, mouth infections, guinea worm sores and jaundice among other (Igbinosa et al. 2011; Donlaporn and Suntornsuk 2010). However, these application of the plant parts is attributed to the vast phytochemicals such as campesterol, pyrimidine-2,,4-dione, curcain, taraxerol, jatropholone A and B etc present in the plant (Mishra et al. 2010; Cano-Asseleih 1986; Hodek et al. 2002). 
Since traditional medicine involves the use of plant extracts which contains an extensive diversity of compounds, often with indefinite biological effects there is need to determine the bioactivity of medicinal plants. The aim of this study is to evaluate the total phenolic content and antioxidant activity, using ferric reducing antioxidant power (FRAP) of the leaf extracts of $J$. curcas.

\section{MATERIALS AND METHODS \\ Collection and Identification and Extraction of Plant Materials}

Fresh leaves J. curcas were collected from the premises of Gwarmai, Bebeji local govt. of Kano State, Nigeria and were identified at the Department of Plant Science, Bayero University Kano, Nigeria. The plant materials were dried in the laboratory at room temperature $\left(26^{\circ} \mathrm{C}\right)$ for 2 weeks, after which it was pulverized into uniform fine powder. The powdered plant materials were weighed using an electric weighing machine and transferred into a conical flask for extraction.

The powdered plant material (200 g) was percolated with $900 \mathrm{ml}$ of ethylacetate and ethanol in a conical flask. It was allowed to stand for 2-weeks before it was filtered. The filtrate was concentrated using rotary evaporator to obtain the ethylacetate and ethanol extracts.

\section{Proanthocyanidin content Assay}

The total proanthocyanidin was determined using the procedure reported by Igbinosa et al. (2011) with slight modification. A volume of 1 $\mathrm{mL}$ of $0.1 \mathrm{mg} / \mathrm{mL}$ of extract solution was mixed with $2.5 \mathrm{~mL}$ of $1 \%$ vanillin-methanol solution and $1.5 \mathrm{~mL}$ hydrochloric acid, the mixture was allowed to stand for 20 mins at room temperature and the absorbance was measured at $500 \mathrm{~nm}$. Total proanthocyanidin contents was expressed as tannic acid $(\mathrm{mg} / \mathrm{g})$ using the following equation of the curve: $y=0.0005 x+$ $0.1967, r^{2}=0.956$, where $x$ is the absorbance and $\mathrm{y}$ is the tannic acid equivalent.

Frap Assay

The reducing power of the extracts was assayed according to the method of Igbinosa et al. (2011) with slight modification. A volume of $1.0 \mathrm{~mL}$ of the extracts, BHT and ascorbic acid (AA) at different concentrations $3.91-500$ $\mathrm{mg} / \mathrm{mL}$ were mixed individually to the mixture containing $2.5 \mathrm{~mL}$ of $0.2 \mathrm{M}$ phosphate buffer $\mathrm{pH}$ 6.6 and $2.5 \mathrm{~mL}$ potassium ferricyanide $\left(\mathrm{K}_{3} \mathrm{Fe}(\mathrm{CN})_{6}\right) \quad(1 \% \mathrm{w} / \mathrm{v})$. The mixture was incubated at $50{ }^{\circ} \mathrm{C}$ for $20 \mathrm{~min}$, followed by the addition of $2.5 \mathrm{~mL}$ of trichloroacetic acid (TCA) and then $2.5 \mathrm{~mL}$ of ferrous chloride $(0.1 \%)$ was added to the mixture. The absorbance was measured at $600 \mathrm{~nm}$ in a spectrophotometer. The higher absorbance of the reaction mixture indicates strong reducing power of the plant extract.

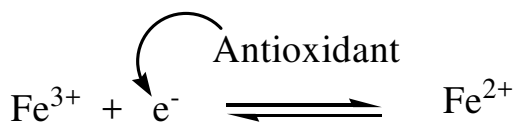

\section{RESULTS AND DISCUSSION}

The present study revealed relatively high level of total proanthocyanidins contents of both the ethylacetate and ethanol extract of $J$. curcas as shown in Table 1. The concentrations of proanthocyanidins contents were expressed as $\mathrm{mg}$ of tannic acid equivalent per gram of extract and the ethanol extracts displayed higher concentration $(357 \pm 12.13 \mathrm{mg} / \mathrm{g}$ TAE $)$ compared to ethylacetate extracts $(159 \pm 0.65$ $\mathrm{mg} / \mathrm{g}$ TAE).

Table 1: Proanthocyanidin contents of the l extracts of the leaves of J. curcas.

\begin{tabular}{lc}
\hline Sample & $\begin{array}{c}\text { Total Proanthocyanidins (mg } \\
\text { tannic acid/g) }\end{array}$ \\
\hline JCEtOAC & $159 \pm 0.65$ \\
JCEtOH & $357 \pm 12.13$ \\
\hline
\end{tabular}

The results showed that there is a strong correlation between total phenolic contents and antioxidant activity $\left(r^{2}=0.956\right)$ such that extract with higher phenolic content displayed the best antioxidant capacity. The antioxidant potentials of the plant extracts was estimated from their ability to reduce $\mathrm{Fe}^{3+}$ to $\mathrm{Fe}^{2+}$. The reducing power of the extracts were observed by change in color from yellow of the test solution that changed to various shades of green and blue depending on the concentration of the plant extracts. The result of the ferric reducing antioxidant power (FRAP) was compared with that of standard butylated hydroxyl toluene (BHT) and ascorbic acid as shown in the chart below. The ethanol extracts which shows higher phenolic content showed high antioxidant activity than the ethylacetate extract which is likely attributed to the presence of phenolic constituents acting as primary antioxidant. 


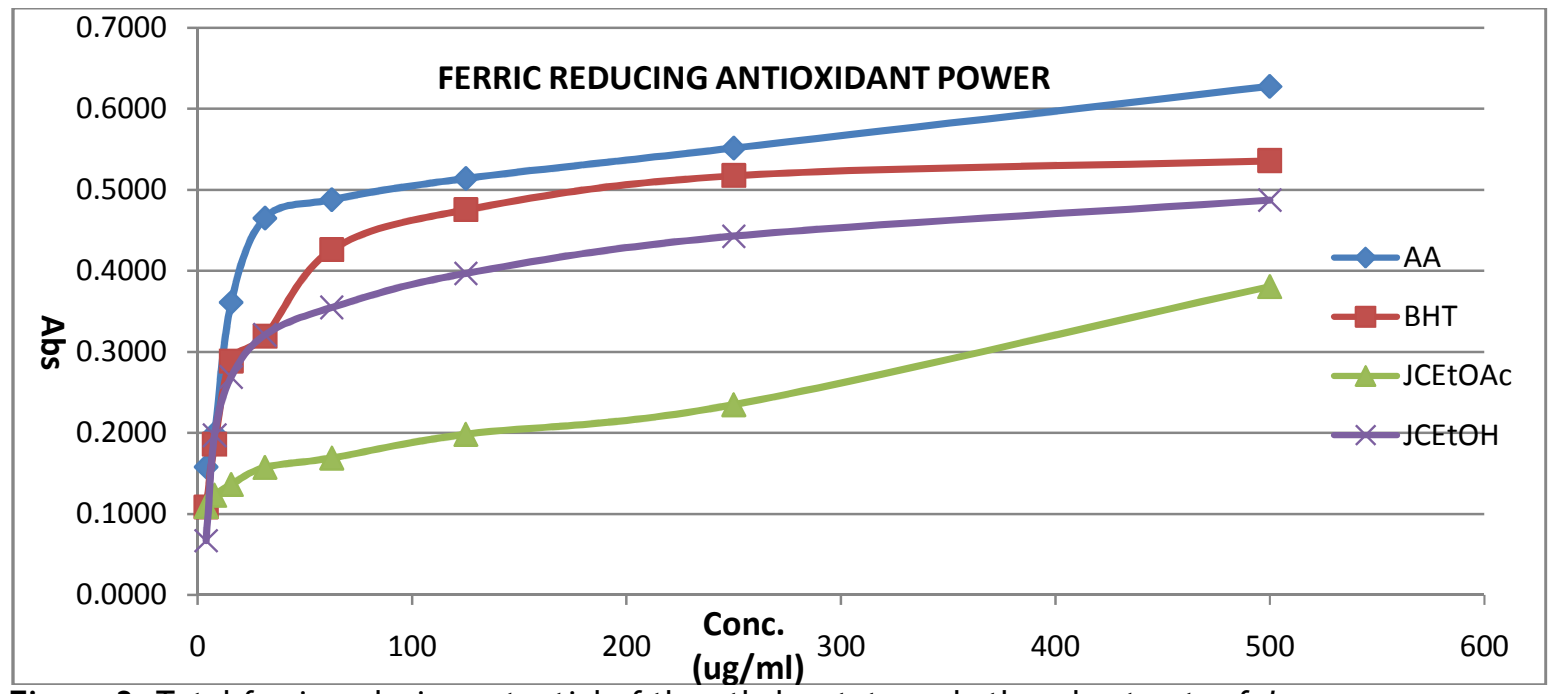

Figure 3. Total ferric reducing potential of the ethylacetate and ethanol extracts of $J$. curcas.

\section{CONCLUSION}

The result of this present study revealed the contents of proanthocyanidin as well as ferric reducing antioxidant power of leaf extracts of J. curcas. The ethanol extracts displayed high antioxidant power than the ethylacetate extracts when compared with the standard BHT and AA which justify the correlation of the phenolic contents and the antioxidant power. The result of this research support the impact

\section{REFERENCES}

Barbosa, N. R., Pittella, F., Dutra, R.C., Junior, D.D., Lopes, M.T.P. (2009). Antioxidant and Cytotoxic Activities of Centella asiatica (L) Urb. Int. J. Mol. Sci. 10: 3713-3721.

Cano-Asseleih, L.M. (1986). Chemical investigation of J. curcas L. seeds. Ph.D Thesis. Univ. London. U.K. 72: 544-546.

De-Oliveira, A.M.F., Pinheiro, L.S., Pereira, C.K.S., Matias, W.N., Gomes, R.A., Chaves, O.S., de-Souza, M.F.V., de Almeida, R.N. and de Assis, T.S. (2012). Total Phenolic Content and Antioxidant Activity of Some Malvaceae Family Species. Antiox. 1: 33-43.

Hodek, P., Trefil, P. and Stiborova, M. (2002). Flavonoids-Potent and versatile biologically active compounds interacting with cytochrome P450. Chem-Bio. Int'l. 139(1): 1-21.

Igbinosa, E.O., Igbinosa, O.O., Igbinosa, I.H., Chigor, V.N., Uzunuigbe, O.E., Oyedemi, S.O., Odjadjare, E.E., and Okoh, A.I. (2011). Polyphenolic Contents and Antioxidant Potential of Stem Bark Extracts from Jatropha curcas (Linn). Int. J. Mol. Sci. 12: 29582971. of this plant in the treatment of various ailments and may be a good candidate for pharmaceutical plant based products.

\section{ACKNOWLEDGEMENTS}

The author will like acknowledge the efforts of Dr. Aminu Muhammad, Department of Pure and Industrial Chemistry and the management of Bayero University, Kano for providing the entire necessary laboratory facilities required for the research.

Kinnula, V.C. and Crapo, J.D. (2004). Super oxide dismuteses in malignant cells and human tumors; free Radical. Bio. Med. J. 36: 718-744.

Mishra, S.B., Kumar, V.M., Ojah, S.K. and Verma, A. (2010). Antidiabetic effect of $J$. curcas leaves extract in normal and alloxan-induced diabetic rats. Intl. gen. pharm. Sci. 2(1): 482-487.

Prior, R.L., Wu, X. and Schaich, K. (2005). Standardised Methods for the Determination of Anti-oxidant Capacity and Phenolics in Foods and Dietary Supplements. J. Agr. Food Chem. 53(10): 4290-4302.

Shahidi, F. (2000). Antioxidant factors in plant foods and selected oil seeds. Int. J. Biofac. 13: 179-185.

Donlaporn and Suntornsuk 2010 